\title{
ORIGEN Y DESARROLLO MORFOLÓGICO DE LA FREGUEZIA SANTA IFIGÊNIA EN SÃO PAULO
}

\author{
Pablo Coquillat Mora \\ Universitat Politècnica de València \\ Director de la tesis: Enrique J. Giménez Baldrés \\ pablocomo@gmail.com
}

\section{RESUMEN}

Este artículo muestra la morfogénesis y desarrollo del barrio de Santa Ifigênia, en São Paulo (Brasil), y lo vincula a la formación de funciones urbanas. Pretendemos constatar la correlación encontrada entre la especialización funcional de áreas urbanas y las transformaciones sufridas por la morfología del barrio. Para ello, se han utilizado las cartografías históricas disponibles de la ciudad de São Paulo que se remontan a 1765 y terminan en nuestros días, con el último Mapeamento Digital da Cidade, de 2004. Las observaciones indican que existe una relación consistente entre la estabilidad topográfica y morfológica de un área y la consolidación de actividades comerciales minoristas en ella.

Palabras clave: morfogénesis, desarrollo morfológico, especialización comercial, Santa Ifigênia

\begin{abstract}
This article shows the morphogenesis and development of the District of Santa Ifigênia, in São Paulo (Brazil), and links it to the formation of urban functions. We intend to verify the correlation found between the functional specialisation of urban areas and the morphological transformations of the neighborhood. We have used historical maps of the city of São Paulo that dates back to 1765 and end up in our days, with the latest Digital Mapping of the City, from 2004. The observations indicate that there is a consistent relationship between topography and morphological stability of an urban tissue and the establishment of retail activities on it.
\end{abstract}

Key words: morphogenesis, morphological development, retail specialisation, Santa Ifigênia 


\section{INTRODUCCIÓN}

La rua Santa Ifigênia en São Paulo está caracterizada por su intensa especialización en la venta al por menor de tecnología popular basada en el sector de electro-electrónicos, informática, iluminación, electrodomésticos, audio y vídeo, instrumentos musicales y accesorios. Su intensificación comercial se remonta a finales del siglo XIX, tras la llegada del ferrocarril a la ciudad a la que acompañó una explosiva llegada de inmigrantes europeos. Desde 1855, primer año del que tenemos registro de la actividad comercial de la vía, hasta la década de 1880, el comercio minorista de la calle creció lentamente, yendo de apenas 2 establecimientos a 24 en el año 1888. A partir de entonces se disparará la actividad comercial de forma exponencial y se mantendrá muy intensa hasta nuestros días, dando lugar a una especialización funcional efectiva de la vía.

Debido a esta continuidad funcional a lo largo del tiempo, el estudio de la rua Santa Ifigênia y del barrio en su conjunto desde el punto de vista de la relación entre funciones urbanas y variación morfológica se presenta muy adecuado. Se trata aquí de analizar las implicaciones del cambio morfológico en tejidos urbanos dominados fundamentalmente por una única función persistente a lo largo del tiempo, con lo cual la heterogeneidad funcional a la que podrían estar sometidos otros tejidos queda eliminada, y ciertas propiedades resultan más visibles.

A lo largo de su historia, la rua Santa Ifigênia ha estado dominada por tres sectores comerciales principales. El más antiguo será el sector de alimentación (1870-1940 aprox.), seguido por el sector de la moda (18702000 aprox), y finalmente el sector tecnológico (1940-). Estos habrán estado complementados con sectores minoritarios con diferente participación en la composición total de actividades de la calle. Tales sectores pertenecen al sector de la construcción, el de productos para la casa, servicios profesionales liberales y otros servicios personales, entre los más destacados.

El análisis tipológico y morfológico contrastado con la evolución comercial ha evidenciado una serie de propiedades importantes. Por un lado, la construcción y transformación edificatoria del barrio muestra ciclos de entre 39-44 años, donde domina alternativamente la renovación y la reforma urbana. Otra constatación dice sobre la influencia de la topografía en la variación morfológica, produciendo que las áreas localizadas en topografías con declividad pronunciada tiendan a ser morfológicamente más inestables que aquellas áreas con topografías regulares. Esta consideración tiene una consecuencia directa para las funciones urbanas, ya que en las áreas de topografía estable las funciones tienden a persistir por más tiempo, sin sufrir grandes alteraciones a lo largo del tiempo, condición ésta que ha permitido la especialización comercial de las áreas topográficas regulares. Debe puntualizarse que la formación de vías comerciales especializadas es un proceso de largo plazo que puede durar desde origen entre 40 y 80 años, y por ello la estabilidad morfológica es un factor determinante para que tal especialización pueda tener lugar. El análisis revela, a su vez, el comportamiento singular de las áreas morfológicas que forman el perímetro de borde entre dos ordenaciones distintas; y constata también la formación de 'irregularidades morfológicas' del tejido.

\section{FORMACIÓN DE LA FREGUEZIA DE SANTA IFIGÊNIA}

La denominación de 'freguezia' se refiere en la cultura luso-brasileña al equivalente de la hispana 'parroquia', entendida ésta como circunscripción territorial que gravita en torno de un templo religioso. En sus orígenes, la freguezia definió el asentamiento del actual barrio Santa Ifigênia cuando en ella se instalara la Basílica de Nossa Senhora da Conceição e de Santa Ifigênia a finales del siglo XVIII y principios del XIX, en sustitución de la antigua Capella de Nossa Senhora da Imaculada Conceição. En aquel entonces, el actual barrio apenas contaba con algunas pocas calles de tierra —entre ellas la primera parte de la rua Santa Ifigênia-, que enlazaban el nuevo asentamiento surgido más allá del riachuelo Anhangabaú al centro histórico consolidado a través del Ponte Acú. 

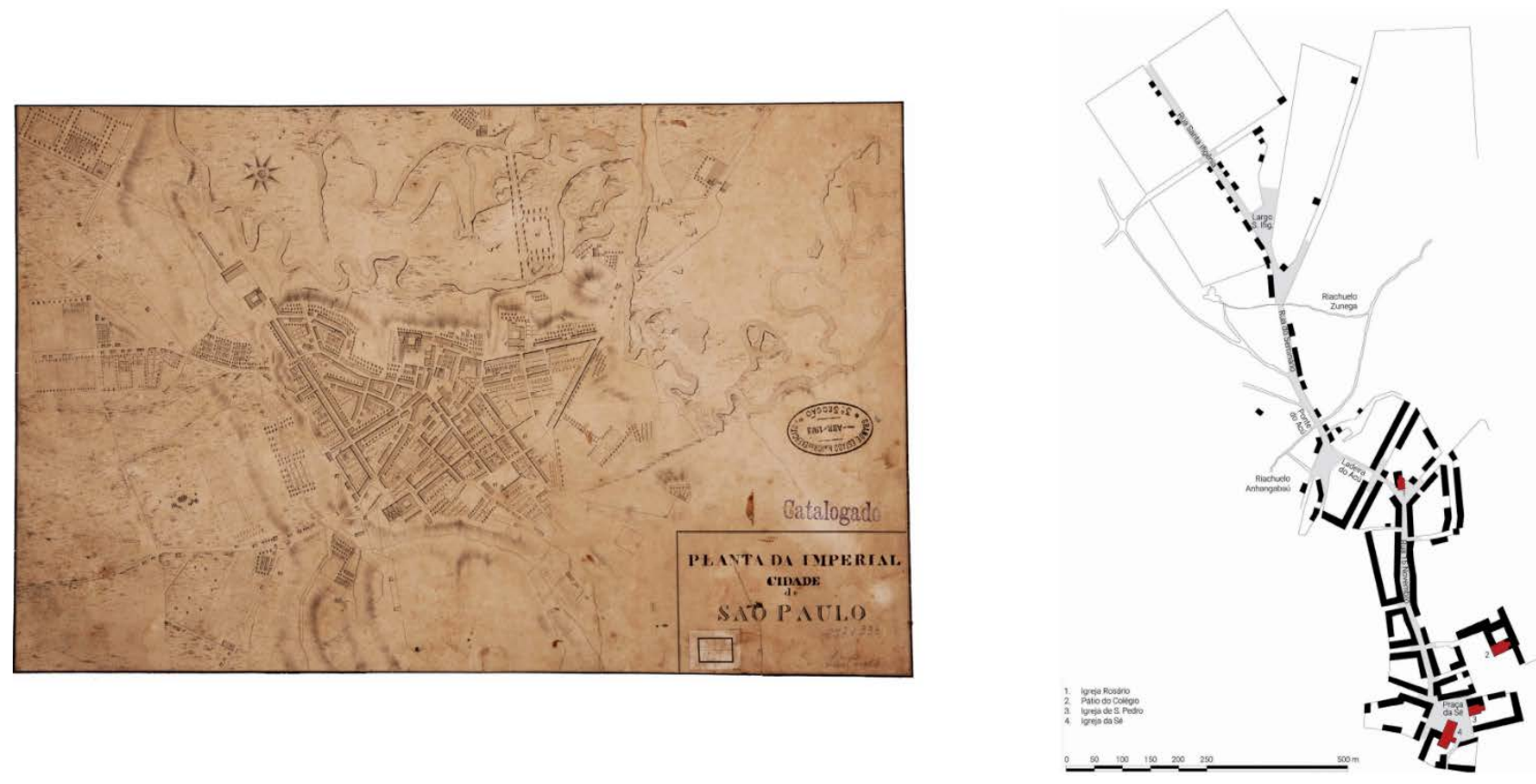

Ilustración 1. Planta da Imperial Cidade de São Paulo, con fecha aproximada entre 1765 y 1774 (izquierda), y diseño del eje de conexión formado por la Rua Santa Ifigênia y la Igreja da Sé, en el centro histórico (derecha).

Elaboración propia a partir de la planta citada.

La expansión que dio lugar a la Freguezia de Santa Ifigênia resultó en el primer ejercicio de crecimiento urbano a modo de 'salto' entre colinas, que será repetido con asiduidad en décadas siguientes. Se trataba de huir de los terrenos pantanosos y cenagosos, y de los fondos de valle sobre los que todavía no se había desarrollado capacidad técnica adecuada para conquistarlos (Ab'Saber, 2004). Por lo que las ocupaciones comenzaron a dispersar por terrazas aluviales o montañosas suaves delimitadas por ríos y riachuelos.

El ancho tablero al noroeste del Triângulo Histórico (así llamado el centro histórico de São Paulo), situado entre 740 y 750 metros de altitud, definía uno de los sectores más amplios y mejor preservados del nivel intermedio del sistema regional de colinas del Planalto Paulistano. Contiguo a la colina histórica, se ubicaba entre 15 y 25 metros por encima del nivel de las grandes planicies paulistanas, y estaba dotada de rampas suaves de acceso hacia los altos del Espigão ${ }^{1}$ Central. Este primer salto urbano de la Freguezia de Santa Ifigênia representó el primer ensayo de un crecimiento a modo de protoensanche, como parte integrante de la llamada 'segunda fundación de la ciudad de São Paulo', según palabras de Eurípedes Simões de Paula en 1936.

La estructura viaria de la nueva región en formación se desplegaba apoyándose sobre las trazas de los cuatro caminos que penetraban el centro histórico atravesando el riachuelo Anhangabaú. Al norte, y entrando longitudinalmente, la rua Florêncio d'Abreu definía el antiguo sendero indígena reabierto por los benedictinos en 1784. En su bifurcación frente al Jardim Botánico daba origen a la rua Allegre, actual Brigadeiro Tobias, la cual servía de eje de apoyo al trazado posterior del barrio. La confluencia de las ruas Allegre y Florêncio d'Abreu continuaría al norte hacia Bragança y al sur del estado de Minas Gerais. Al centro de los terrenos, y penetrando perpendicularmente al casco histórico a través del Ponte Marechal o Acú, la rua São João vertebraría las dos ordenaciones independientes que delimitaba. Casi paralelamente a ésta, el camino de Parnahyba, Itú y Jundiaí convergía al sudoeste del Triângulo Histórico en el Obelisco do Piques, donde finalmente, se cerraba la estructura viaria al sudoeste con el inicio de la rua Consolação que seguiría hacia el camino de Pinheiros y Sorocaba. Éste último daba servicio a las regiones meridionales del Brasil, productoras de ganado vacuno y mulas.

\footnotetext{
${ }^{1}$ La línea divisoria topográfica más alta o cumbre, donde se han instalado ejes vertebradores de la movilidad como la famosa Avenida Paulistana.
} 


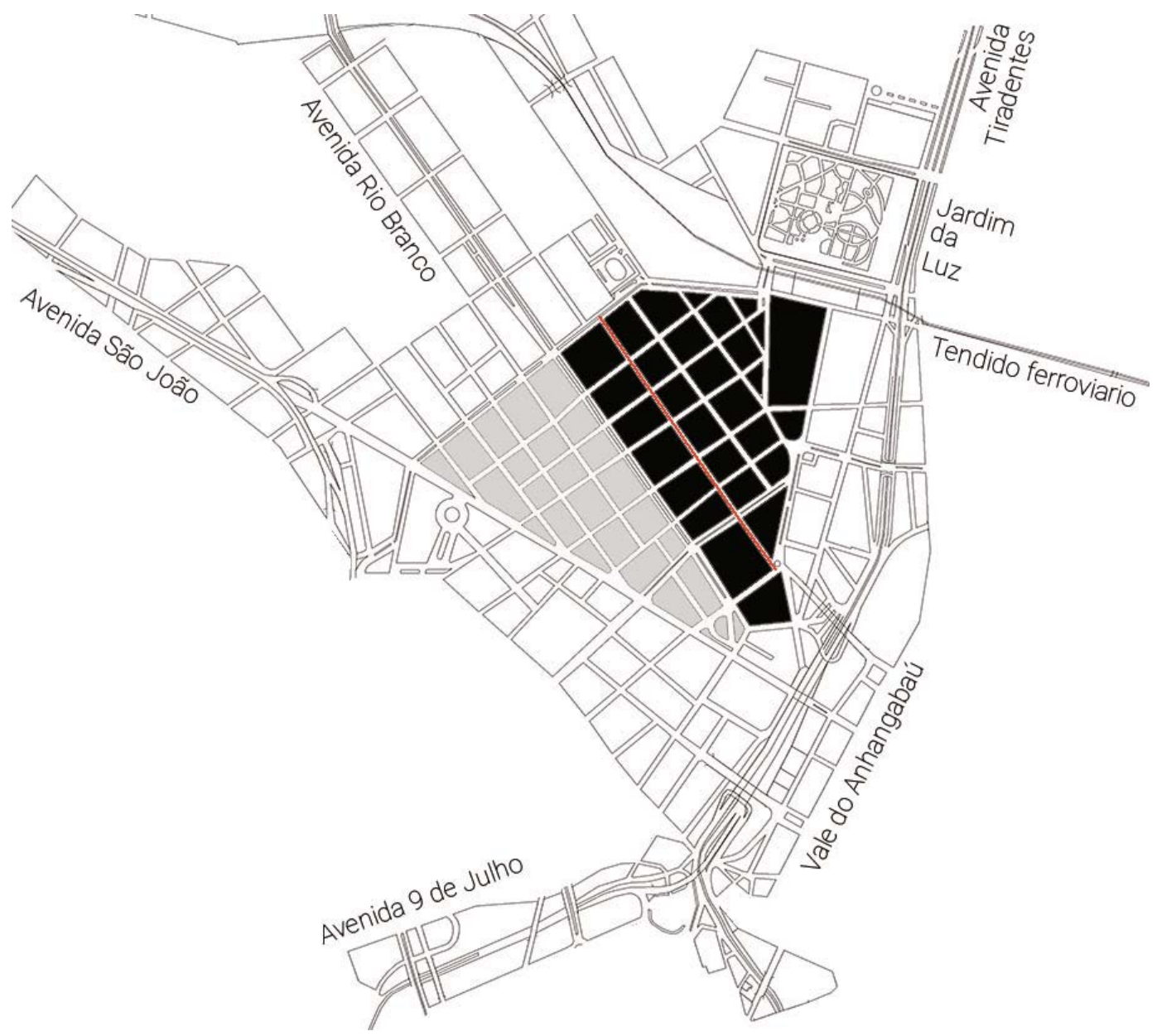

Ilustración 2. Señalización de avenidas y elementos importantes con relación al ámbito de Santa Ifigênia Elaboración propia según Mapeamento Digital da Cidade 2004.

En este primer cordón perimetral del centro histórico las chácaras ${ }^{2}$ presentaban dimensiones comparativamente menores a aquéllas más alejadas. El trazado viario se resolvía salvando a su paso propiedades rurales que quedaban incorporadas al ámbito urbano, pero sin producción inmobiliaria significativa. El encaje del trazado entre los huecos sobrantes de las chácaras iba teniendo lugar progresivamente a medida que se incorporaban caminos al dominio público en propiedades reparceladas.

La conversión de suelo rural a suelo urbano se dio en Santa Ifigênia de igual modo a como ha sido descrito para varias ciudades europeas (Barras, 2009; Gimenez Baldrés, 1996; Solà-Morales, 1997), esto es, usando los caminos rurales para delimitar los ámbitos de ordenación y las calles, y subdividiendo las chácaras en calles ortogonales con una alineación acorde a la de los caminos perimetrales. Por consiguiente, las trazas agrícolas pasadas definen una herencia morfológica relevante en la ciudad nueva.

\footnotetext{
2 Las 'chácaras' corresponden a pequeñas propiedades rurales, periurbanas o urbanas, con residencia para vivir, cría de animales y cultivo de frutas y hortalizas para venta. En algunos casos se podría equiparar a las 'fincas' o 'granjas' españolas. En tiempos más recientes, las chácaras han adquirido la función de segunda residencia destinada al ocio y recreación de fin de semana, ubicándose próximas a los núcleos urbanos.
} 


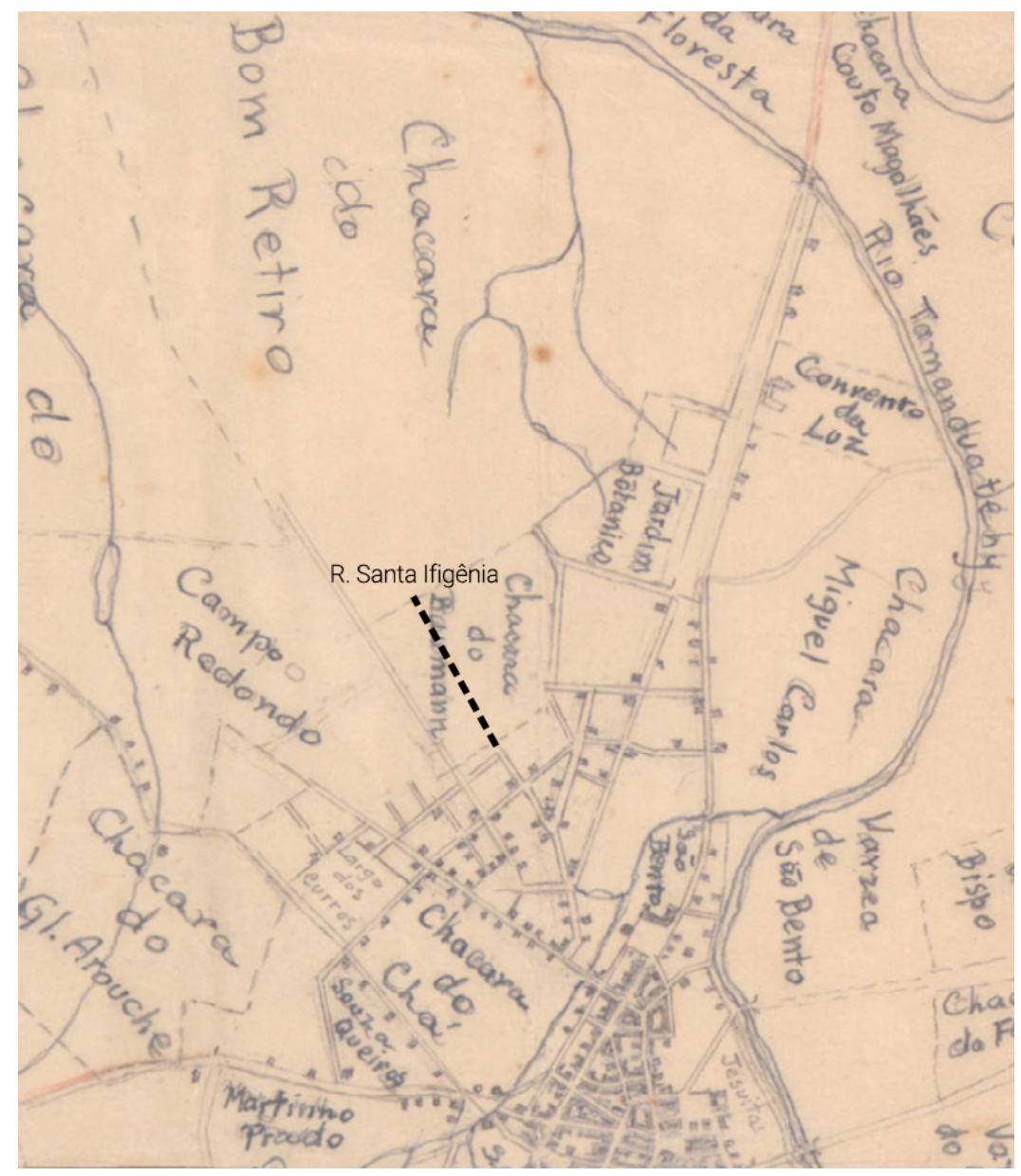

Ilustración 3. Planta das Chácaras, sítios e propriedades à volta da Cidade de São Paulo, desde o século XVIII (São Paulo, n.d.).

Arquivo Aguirra, Acervo del Museu Paulista de la USP, São Paulo.

No se trataría todavía de una solución genuinamente en ensanche, ya que la expansión no fue planificada bajo un proyecto único y globalizante, con una única unidad de gestión, un área claramente delimitada, o un promotor único (o incluso múltiple). En su lugar, las trazas continuaban las líneas de calles que alcanzaban al ámbito de expansión, y serían atravesadas por calles paralelas a una distancia de entre 70 a 115 metros.

El importante salto demográfico que la ciudad de São Paulo habría de recibir en la segunda mitad del siglo $\mathrm{XIX}^{3}$, impuso un régimen de atención urbanística centrado en dos aspectos básicos: la ordenación de los terrenos amorfos periféricos, dominados por los ríos y sus zonas de inundación, y la dotación de un sistema de agua potable masivo. En el Mappa da Imperial Cidade de São Paulo de 1855 se dibuja explícitamente la interacción del municipio con la red hídrica del cinturón urbano —ver ilustración 3. En él, se observa cómo las zonas húmedas 'secuestran' las posibles áreas contiguas al núcleo por donde podría discurrir el crecimiento, obligando a la administración a realizar obras de porte que superasen tal restricción morfológica. En este sentido, la actuación más relevante se dirigirá a la rectificación y canalización del Río Tamanduatei, bajo la falda este del Triângulo Histórico.

\footnotetext{
3 La población cuadruplicó en una única década, pasando de 64.934 habitantes en 1890 para 239.820 en 1900.
} 


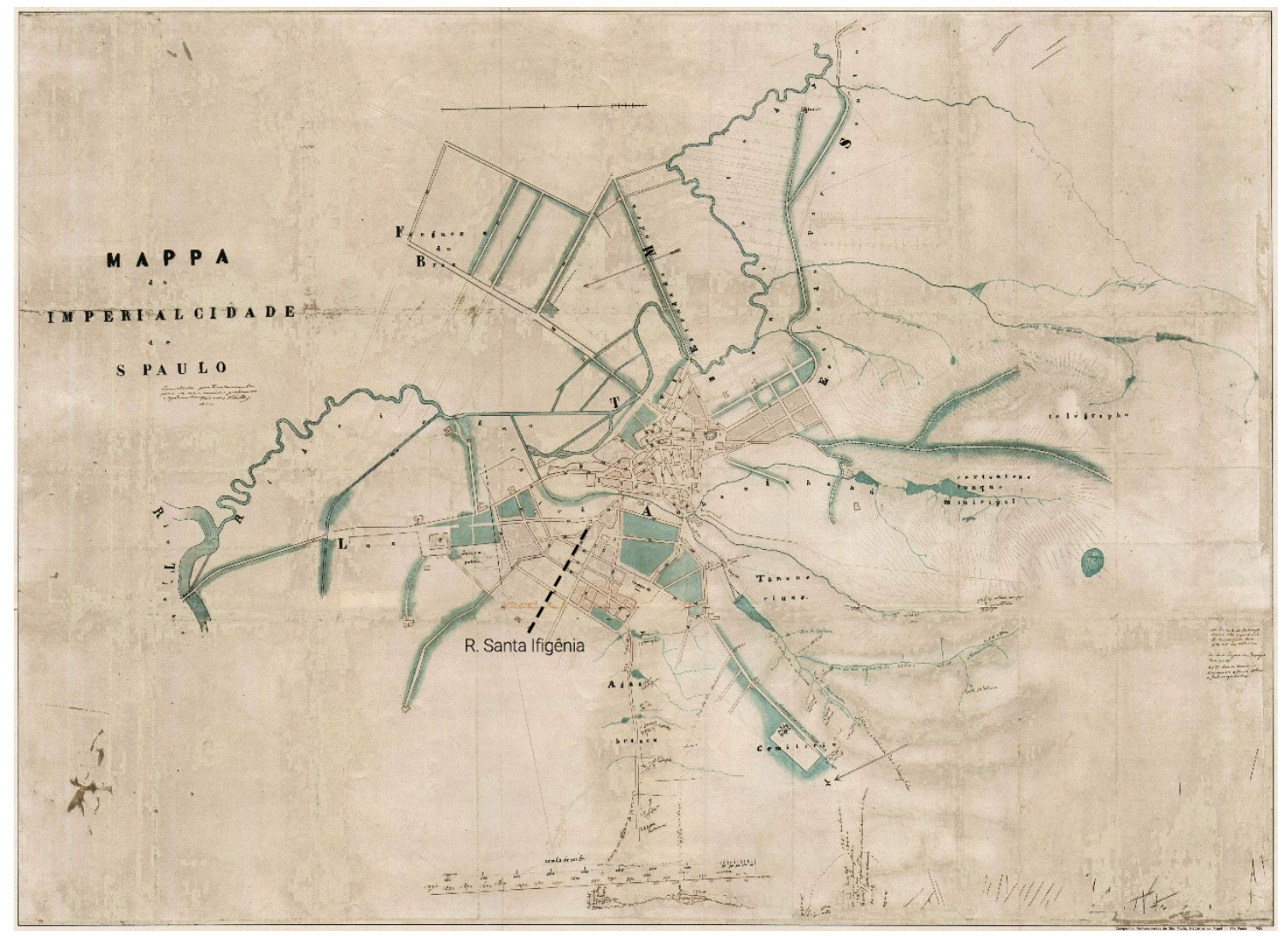

Ilustración 4. Mappa da Imperial Cidade de S. Paulo, 1855.

Arquivo Histórico Municipal de São Paulo

Por otro lado, y acompañando al proyecto de canalización, un extenso programa de obras hidráulicas buscará resolver en estas décadas los problemas sistémicos de suministro de agua potable y de saneamiento de áreas inundables donde aumentaba el riesgo de proliferación de enfermedades. En primer lugar, serían las obras de chafarizes $^{4}$, que suministraban agua potable proveniente de tanques periféricos enlazados a través de cañadas a cielo abierto, siendo estas últimas sustituidas por cañerías de hierro fundido a partir de 1851. En segundo lugar, y con un coste más elevado, se acometerán proyectos de estudio de fuentes distantes de suministro de agua potable, a los que seguirán las obras hidráulicas que traerían el agua al municipio, dándose origen con ello a importantes parques estatales protegidos al norte y sur de la capital ${ }^{5}$.

\section{DESARROLLO MORFOLÓGICO DEL TRAZADO URBANO DE SANTA IFIGÊNIA}

Según Eudes Campo $^{6}$, el arruamento $^{7}$ de la chácara Campo Redondo que ocuparía el barrio de Santa Ifigênia tuvo lugar en 1859, entrando en contradicción con la Planta da Cidade de São Paulo de 1868, donde todavía aparece esta área esbozada a lápiz. En cualquier caso, se desprende que el arruamento del barrio de Santa Ifigênia se estaba produciendo entre las décadas de 1850 y 1860 a partir de una ocupación progresiva de edificaciones aisladas.

\footnotetext{
${ }^{4}$ Los 'chafarizes' equivalen a las fuentes públicas de suministro de agua potable utilizadas antaño.

${ }^{5}$ El Parque Estadual da Cantareira y el Parque do Estado.

${ }^{6}$ Ibidem.

${ }^{7}$ El término deriva del acto de trazar las vías o ruas, o arruar. Puede interpretarse equivalente a 'urbanización'.
} 
La ilustración 3, muestra que la expansión del barrio hacia el norte sólo pudo ocurrir a partir de la transformación de las chácaras del Coronel Gavião y de Campo Redondo a suelo urbano, retirando el tapón que éstas introducían. Al interior de éstas, la estructura se resolvería mediante una malla cuadrangular.

La serie de cartas de la ciudad elaboradas durante la segunda mitad de siglo XIX muestran un grado de variación significativo en la morfología de Santa Ifigênia, hasta que por fin se consigue estabilizar la mayor parte de su trazado. La primera constatación de las intenciones de ordenación de la freguezia aparece en el Mappa da Imperial Cidade de São Paulo, datado de 1855, y posteriormente en la Planta da Cidade de São Paulo - 1868, ambas esbozadas a lápiz y de autoría del ingeniero alemán Rath. En aquella primera, el trazado titubea entre varias alineaciones que buscaban continuar las calles colindantes. Apenas la actual rua dos Gusmões parecía existir en aquella época. El borde de la expansión alcanzaba la chácara de Campo Redondo, buscando alineación con el Jardim da Luz, pero más tarde se vería alterada por el paso de la línea ferroviaria, evitando el enlace directo entre el Jardim y el nuevo barrio.

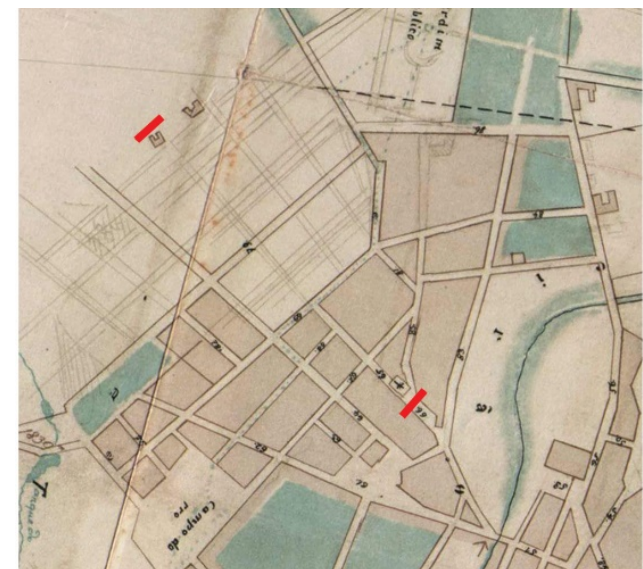

a. 1855

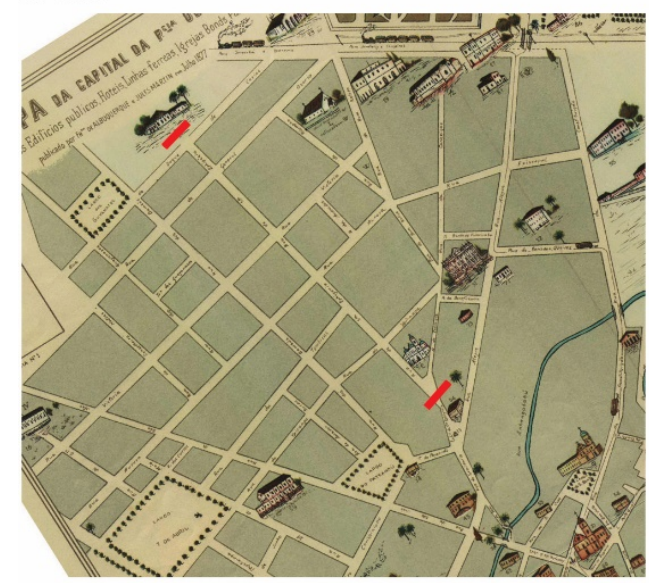

c. 1877

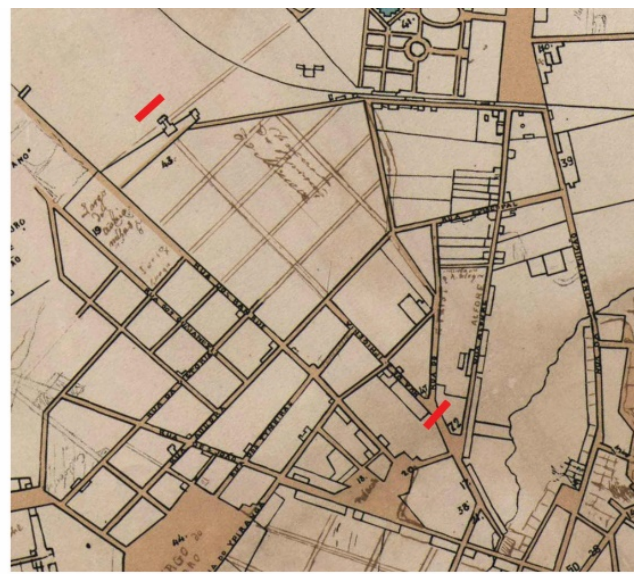

b. 1868

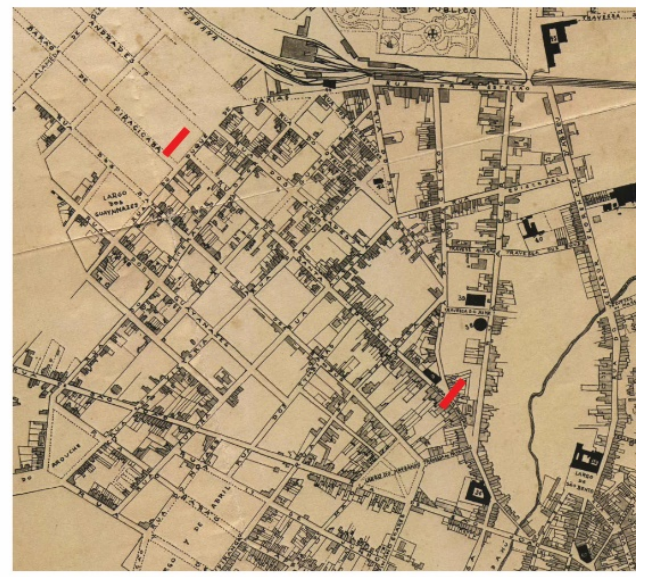

d. 1881

llustración 5. Variación morfológica del área de Santa Ifigênia en los años 1855, 1868, 1877 y 1881 . Se demarca en rojo el inicio y fin de la rua Santa Ifigênia.

Arquivo Histórico Municipal

En la Planta da Cidade de São Paulo - 1868 ya aparece la intersección del barrio con el tendido ferroviario en el lado norte, mientras que el ensanche esbozado por Rath en la carta del 1855 es corregido, creando ahora una ordenación regular de calles en dirección este-oeste, y otra con distancias variables en dirección nortesur, cuyos trazados daban continuidad a las existentes calles Santa Ifigênia y do Triunfo.

Es en el Mappa da Capital da P.cia de S. Paulo 1877 donde por vez primera aparece definido la ordenación del barrio con trazo fijo. La urbanización y reparcelación de las antiguas chácaras había dado paso a manzanas de dimensiones irregulares, con trazados viarios que aquí y allí se interrumpían debido a que el proceso de subdivisión no alcanzó a todas las manzanas por igual. De ese modo se configuraba todavía un ensanche polimorfo de calles sin jerarquía aparente; el ancho del viario se acotaba al entorno de los diez 
metros y medio, y sólo ahora aparecerían edificaciones singulares que comenzaban a polarizar la atracción hacia algunas zonas. El tren llegó en 1865, y el área envolvente de la estación comenzó a ser ocupada con edificaciones auxiliares significativas: la Estação da Luz, la Estação de Bonds de Luz, la Fundição da Luz, la Estação Sorocabana, las Officinas da Companhia Inglesa, el Hotel Albião o la Igreja Evangélica.

Tan solo cuatro años después, la Planta da Cidade de São Paulo levantada pela Companhia Cantareira e Esgotos 1881 mostrará una nueva reparcelación de las manzanas mucho más parecida a la actual conformación del trazado, restando apenas la gran manzana entre las calles Aurora, Ipiranga, Santa Ifigênia y Bom Retiro (actual R. Gral. Couto de Magalhães) como elemento que resistió la segregación durante casi cincuenta años más. Esta manzana parece corresponder a la antigua chácara propiedad de la abastada $\mathrm{D}^{\mathrm{a}}$. Marianna Fortes, importante rentista de la época con once casas más de alquiler además de su propia residencia, encontrándose esta última localizada en el ángulo sudeste de la referida manzana.

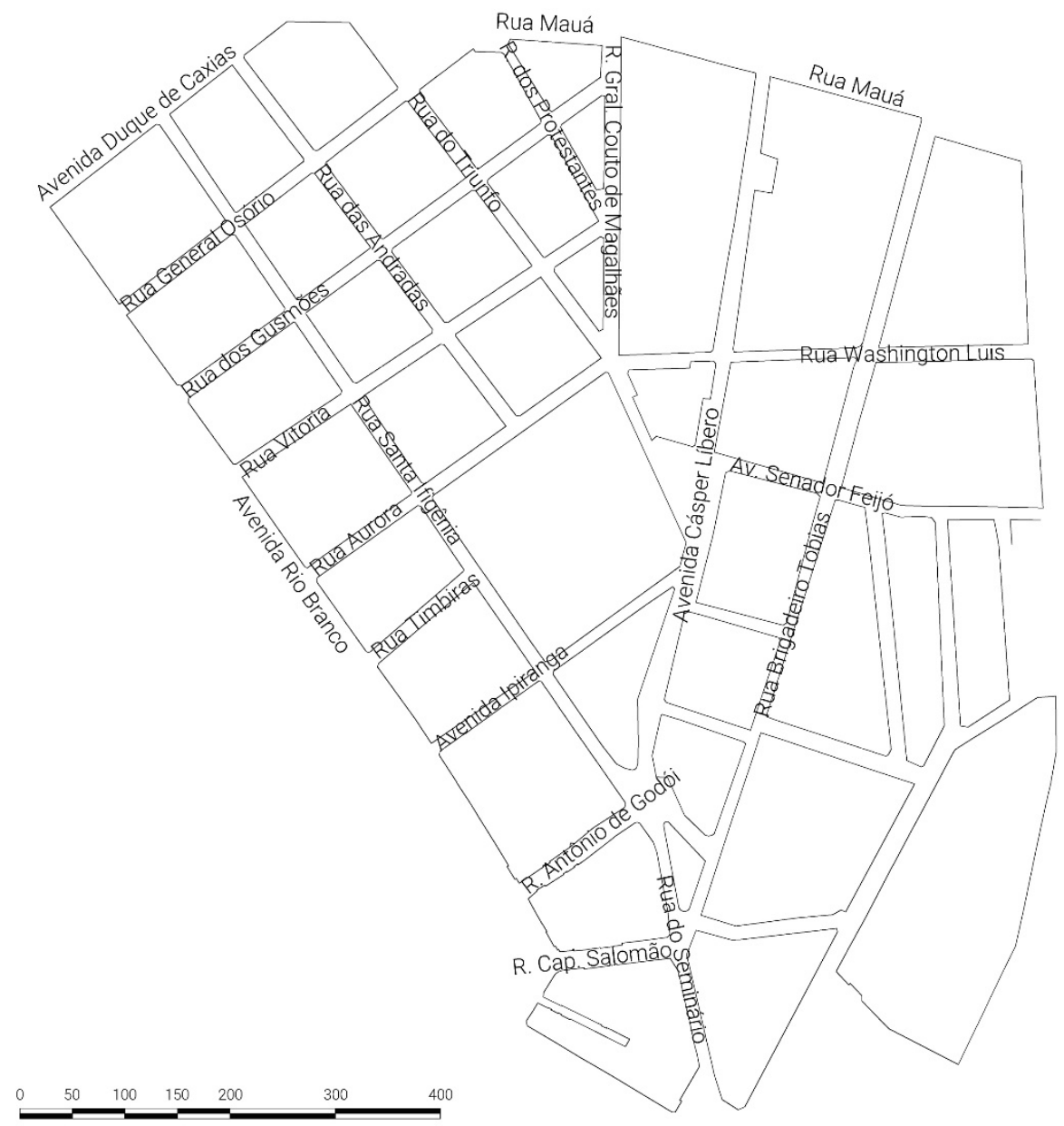

Ilustración 6. Indicación de vías del barrio Santa Ifigênia.

Elaboración propia según plano Sara Brasil de 1930.

\subsection{Características morfológicas de la urbanización}

El área de estudio de nuestro análisis estará básicamente conformada por dos ámbitos principales de ordenación. El primero y más antiguo pertenece al ámbito que creció lentamente sobre la margen izquierda del riachuelo Anhangabaú, cuya dirección S-N venía marcada por los caminos de salida de la ciudad hacia el norte. Este trazado será más irregular, de formatos y dimensiones más diversas, y apoyado sobre el perfil topográfico más accidentado del área analizada. El segundo ámbito de ordenación viene definido por la extensión a modo de ensanche en dirección SE-NO, localizada en el cuadrante izquierdo superior, con una urbanización cuadrangular mucho más regular que la del ámbito primero, y asentado sobre una planicie topográfica de escasa variación planimétrica —ver ilustración 7. La distinción entre ambas es fundamental para entender su comportamiento evolutivo posterior. 


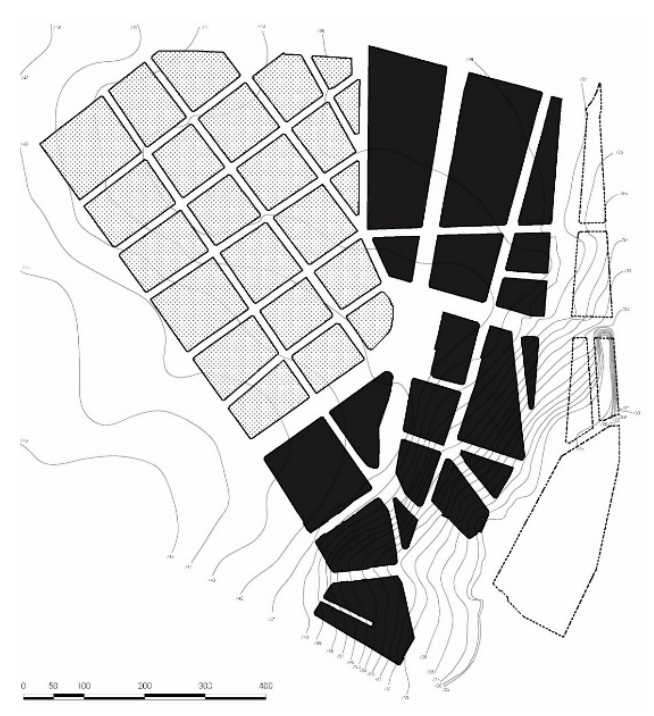

Ilustración 7. Ámbitos de ordenación morfológica en Santa Ifigênia Elaboración el autor.

\subsubsection{Variación morfológica}

La transformación morfológica de las quadras ${ }^{8}$ muestra una tendencia progresiva hacia la reducción de las dimensiones originales a tamaños convergentes y menores. Mediante el análisis de la forma y dimensión de las quadras en los períodos 1881, 1892, 1930, 1954 y 2004 —ilustración 8 y 9-, es posible constatar el proceso de fragmentación y encaje al que ha sido expuesto el trazado urbano de Santa Ifigênia a lo largo de su historia. Los períodos elegidos corresponden con las cartas de la ciudad de São Paulo donde aparecen grafiadas la parcelación y urbanización del barrio completo, desde la primera planta que contiene tales informaciones de 1881. El rango métrico en que están comprendidas las dimensiones de las quadras en el año 1881 es el mayor de toda la serie, con un 50\% de los tamaños entre los 7.500 y 19.000 metros cuadrados, un $95 \%$ del total entre 2.000 y 34.000 metros cuadrados, y un valor excepcionalmente alto de la quadra ubicada en el Vale do Anhangabaú, con origen en la rua do Seminário y fin en la entonces Travessa dos Bonds. Dicho rango irá en disminución en los siguientes períodos analizados, tendiendo a estabilizarse a partir de la configuración morfológica mostrada en la planta VASP Cruzeiro de 1954.

La lectura de los valores según la planta de 2004 constata la reducción y concentración de los valores medios de la morfología urbana. Un 50\% de las quadras presentará ahora tamaños comprendidos entre los 5.000 y 10.000 metros cuadrados aproximadamente, el 95\% de los tamaños totales estarán comprendidos entre los intervalos 1.000 y 15.000 metros cuadrados, y finalmente existirá un $5 \%$ de valores inusualmente altos, correspondiente a las quadras 19, 20, 49 y 53 -ver ilustración 6-, llegando a alcanzar en el mayor caso los 38.400 metros cuadrados. Dicha tendencia está indicando un proceso bastante intenso de ajuste y reducción del tamaño de manzanas en áreas que han sido especialmente expuestas al cambio morfológico.

8 Literalmente, 'manzanas'. 


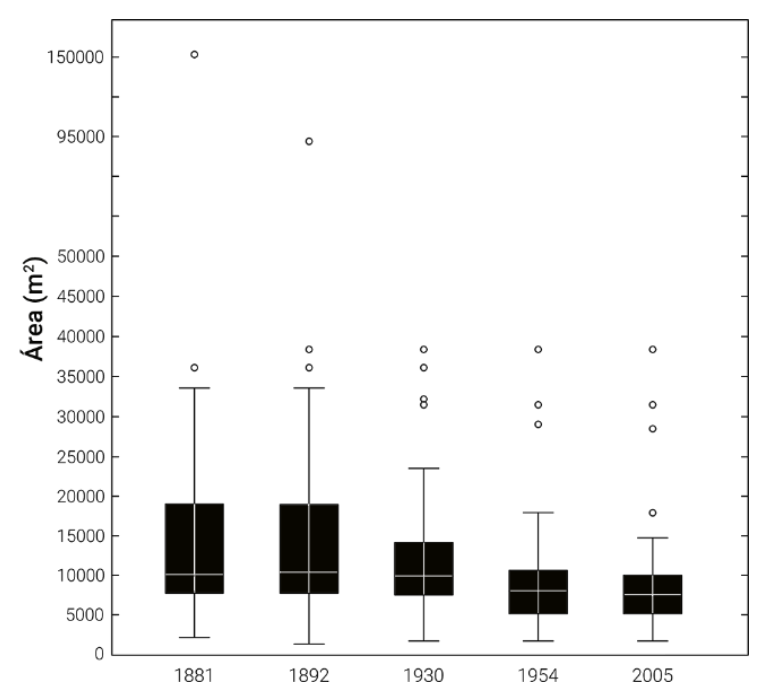

Ilustración 8. Variación del tamaño de quadras en el barrio Santa Ifigênia para los años 1881, 1892, 1930, 1954 y 2005. Elaboración el autor.

La ilustración 9 muestra la superposición morfológica del barrio en los cinco períodos mencionados. La mayor presencia de ajustes morfológicos se da en la región ubicada en el ámbito del riachuelo Anhangabaú y en las quadras contiguas. La presencia del río y el valle, y las sucesivas actuaciones sobre estos, han dado lugar a diferentes ordenaciones con un proceso de ocupación caracterizado por el llenado inicial con edificación y su posterior vaciado, fruto de la abertura de la rua Anhangabaú — década de 1890- y, posteriormente, la Avenida Prestes Maia y las Praças Predro Lessa y Correios — década de 1930.

Hasta los años 1930 se dieron algunas operaciones de expropiación de pequeño calado que buscarán adecuar calles con mayor intensidad de uso. Entre ellas, la rua Santa Ifigênia, con expropiación de unos dos metros y medio del lado impar mediante la Lei no 1.834 de 1914; la rua Conceição, actual Cásper Líbero, con expropiaciones en curso en aquellos años; la rua Washington Luís; o la rua São João, ésta sí con una importante expropiación de unos veinte metros de su lado par. La Avenida Prestes Maia aparece ya marcada en el SARA Brasil de 1930, aunque la edificación sólo será expropiada a finales de la década de 1930, concomitantemente a la expropiación de la Avenida Duque de Caxias, cuando se acometieron las obras del Plano de Avenidas de Prestes Maia. Salvo estas últimas, las anteriores expropiaciones suponen operaciones menores si las comparamos con las llevadas a cabo a partir de dicho Plano de Avenidas.

El anillo de circunvalación pretendido ya desde el Perímetro de Irradiação de Ulhoa Cintra en los años 1920, y sobre el que se basó el Plano de Avenidas, se concretará en la década siguiente con ciertas alteraciones en la elección de las calles ${ }^{9}$, trasladando importantes expropiaciones a las ruas Senador Queiroz e Ipiranga, convertidas consecuentemente en avenidas. El enlace entre dichas avenidas se daba a través de una quadra triangular que había sufrido reducciones dimensionales importantes en tiempos pasados, localizada entre las calles Cásper Líbero, Washington Luís y General Couto de Magalhães - correspondiente a la quadra número 26. Este enlace del perímetro de circunvalación se resuelve principalmente sobre quadras y lotes ${ }^{10}$ con muy baja densidad. Según la numeración de la ilustración, la quadra 36 estaba ocupada tan sólo por cinco edificaciones, la mayor de las cuales era el hospital de Beneficência Portuguesa, mientras que las restantes construcciones liberaban bastante área en sus respectivos lotes. La quadra 95 estaba constituida en su mayoría por la edificación ya comentada de $\mathrm{D}^{\mathrm{a}}$. Marianna Fortes y las dos construcciones vecinas también poco densificadas.

De modo que la expropiación de terrenos iba teniendo lugar en aquellas calles donde la edificación no había avanzado tanto, donde la presencia de propiedades antiguas, de residencias unifamiliares principalmente, había preservado grandes áreas urbanas sin edificación, y los costes de indemnización, en consecuencia, se reducían. La baja densidad señala, pues, los espacios preferentes de la expropiación.

\footnotetext{
${ }^{9}$ Tal sería el caso, por ejemplo, de la expropiación sobre la rua Ipiranga, prevista inicialmente según el Perímetro de Irradiação sobre la paralela rua Timbiras.

10 Literalmente, 'parcelas'.
} 


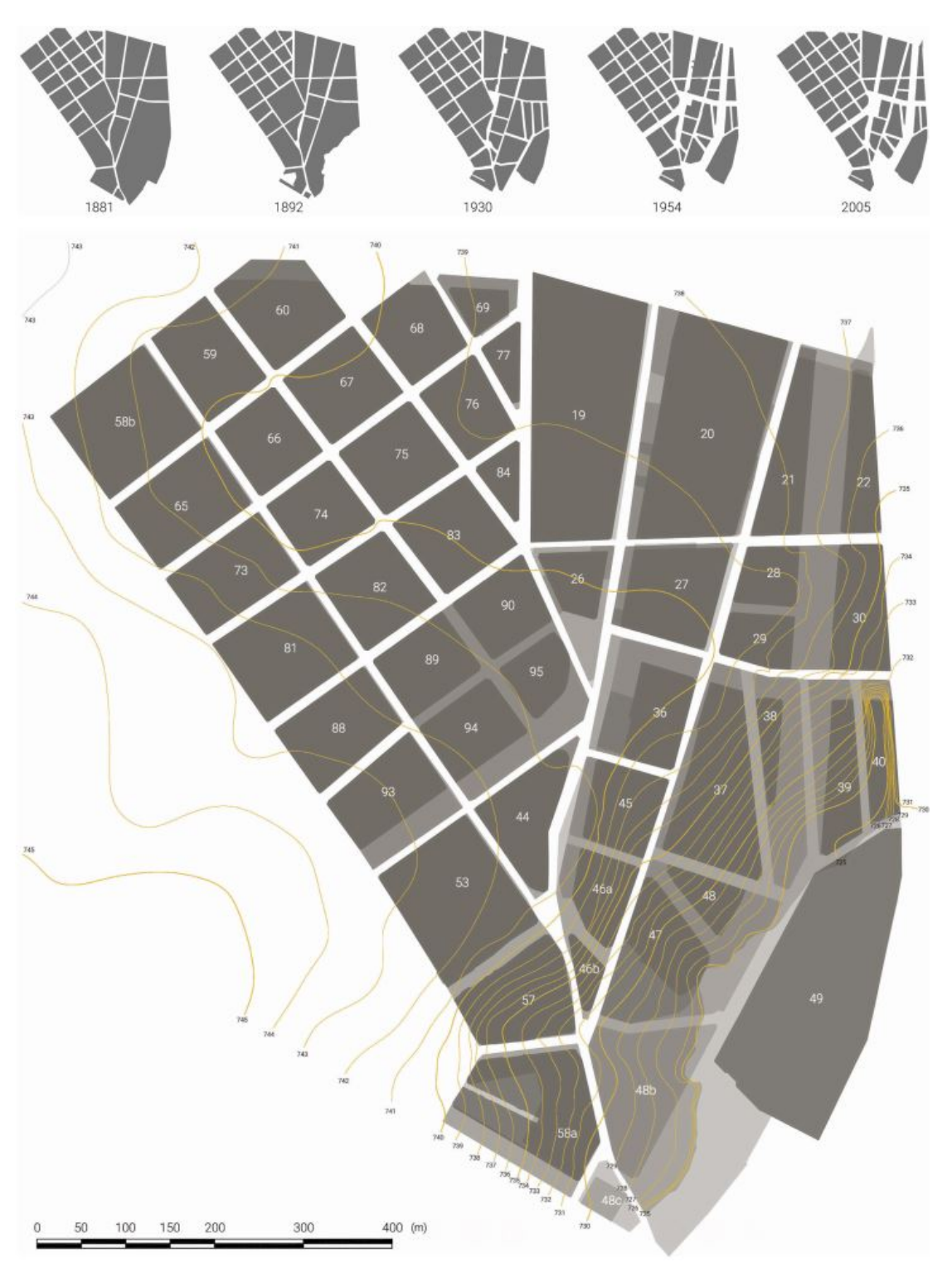

llustración 9. Superposición de la urbanización en Santa Ifigênia según su estado para los años 1881, 1892, 1930,1954 y 2005. Elaboración el autor.

De forma similar ocurre con la gran quadra ubicada en el Vale do Anhangabaú. En este caso, las condiciones topográficas y el paso del riachuelo dificultaban la ocupación del área. El lecho del riachuelo determinará morfológicamente varios de los estadios de la urbanización, que se hicieron servir de éste para definir el límite posterior de quadras a inicios del siglo XX, mediante el soterramiento y canalización del río y la creación de la rua Anhangabaú. Con la inauguración en 1913 del Viaduto de Santa Ifigênia, enlazando sendos largos de São Bento y Santa Ifigênia, se debilitaría la estructura de aquellas quadras cortadas, introduciendo una nueva directriz de ordenación que servirá posteriormente como remate norte del Vale do Anhangabaú —ver ilustración 8. Tras los primeros vaciados de edificación fueron sucediéndose pequeñas subdivisiones de las quadras, suprimiéndose cada vez más área edificada, hasta alcanzarse en 1954 una situación similar a la existente en la actualidad, con el gran vacío introducido por la Avenida Prestes Maia. 


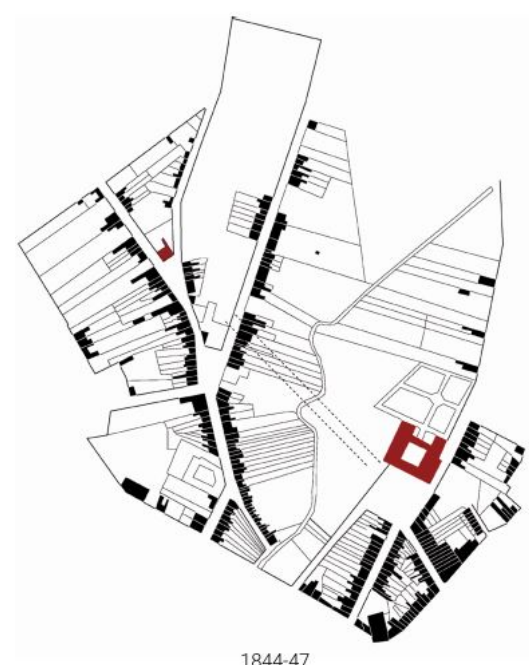

$1844-47$
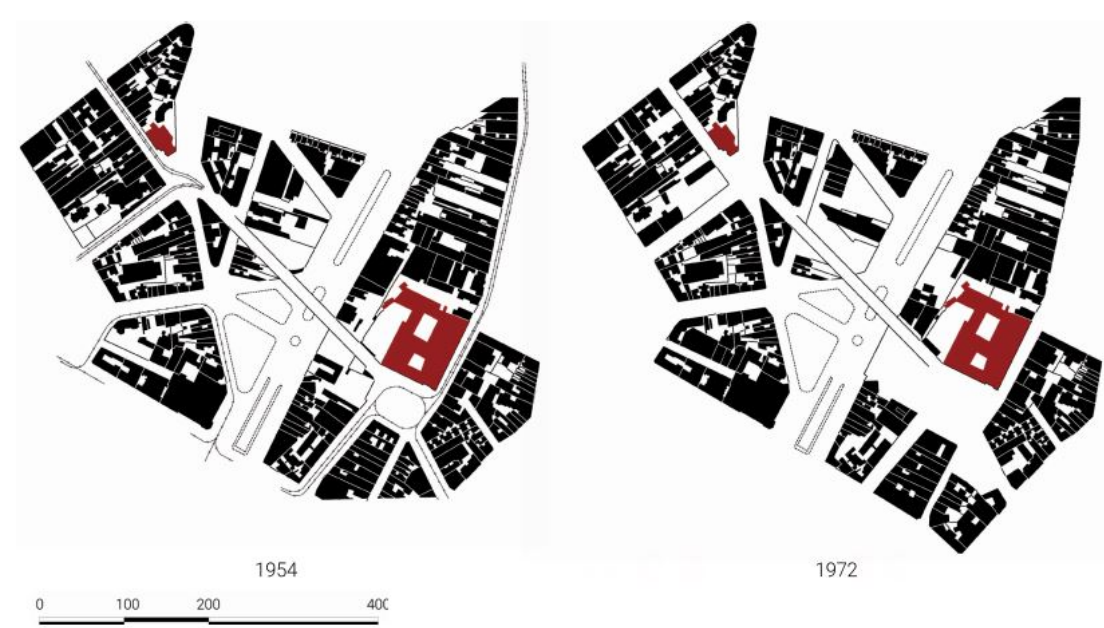

1972

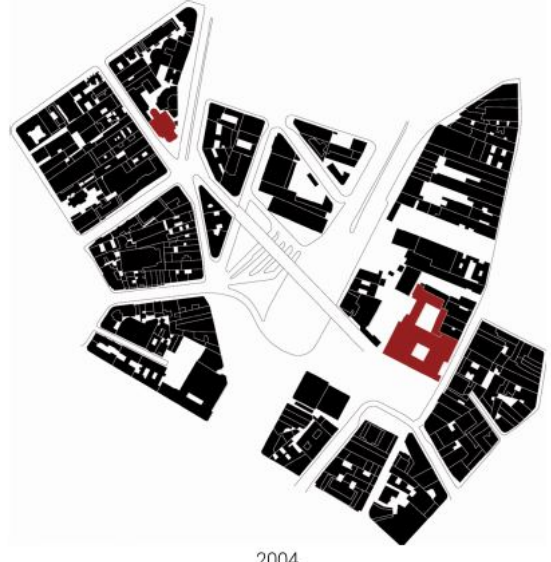

2004

Ilustración 10. Variación del tejido urbano afectado por el Viaduto de Santa Ifigênia. Elaboración el autor.

El Largo de Santa Ifigênia, así como el eje formado por la Avda. Cásper Líbero que lo acompaña, también fueron sufriendo sucesivos ajustes morfológicos. La avenida vio recortar principalmente su lado par, y con ello se amplió el área del Largo frente a la parroquia. Es posible apreciar cómo surge el característico quiebro de la quadra 44, donde se ubica la iglesia, a consecuencia de la expropiación que hizo perder el paralelismo entre los lindes edificatorios, generándose así un espacio sobrante a modo de largo.

Hasta ahora nos hemos referido básicamente a las transformaciones morfológicas del área este del barrio. El lado oeste está conformado en su mayoría por el ensanche en cuadrícula de 1859 — según fecha de Eudes Campos-, y donde se encuentra la mayor parte del recorrido de la rua Santa Ifigênia. Este ensanche ha sufrido intervenciones de ajuste de su morfología menores que el lado opuesto, tanto en número como en tipo. Las intervenciones más importantes serían, por un lado, la conversión de la chácara de $D^{a}$ Marianna Fortes de una a cuatro quadras; por otro, la expropiación de unos veinticinco metros del lado impar de la rua Ipiranga; y, finalmente, operaciones de corrección puntual en las quadras 60, 68, 69 y 77, al norte. Éstas últimas buscarán ampliar el cinturón viario que enlaza la Estação da Luz al Largo de Arouche a partir de la rua Mauá y la Avda. Duque de Caxias. La expropiación ocurrida en la rua Santa Ifigênia se dará en dicho lado oeste, sin embargo, no supuso una diferencia de grado en la morfología del barrio.

Una nueva transformación se daría en la morfología urbana a partir del año 1912. Se trata de la aparición y regulación del chaflán en las esquinas de manzanas, de como mínimo tres metros y medio de longitud. Cualquier interesado en realizar obra mayor en su edificación estaría obligado a corregir la esquina mediante chaflán. Este requisito de diseño de las manzanas vendría recogido por la Lei nº 1.585 de 1912. 
Con todo, el trazado del área en ensanche ha sufrido una variación morfológica mucho menor que el resto del barrio. Y es remarcable que esto suceda en las zonas más nuevas del mismo, dado que el lado este, más próximo al Triângulo Histórico, ya aparecía en las plantas de 1810, unos cincuenta años antes de la existencia del ensanche. Este hecho apunta a dos razones explicativas complementarias.

En primer lugar, la proximidad del área contigua a la colina histórica se desarrolló sobre las márgenes del riachuelo Anhangabaú, sobre un terreno inestable en declive que invitaba a una ocupación más extensiva que intensiva. En consecuencia, se irían formando manzanas de baja densidad. La ubicación de la estación de ferrocarril y la salida norte en dicho ámbito, a su vez, elevaba su centralidad como nodo de movilidad, lo cual motivó que las vías allí surgidas, gracias al soterramiento y canalización del Anhangabaú, fuesen reconvertidas a ejes importantes de movilidad. Recordemos que la ocupación de los fondos de valles como ejes vertebradores del sistema viario es un morfologismo recurrente en el planeamiento paulistano. Por tanto, la indefinición morfológica de las áreas ribereñas, en primera instancia, y la oportunidad derivada de la cultura de utilización de los cursos de agua como ejes viarios, en segunda, han propiciado la extensa gama de variaciones morfológicas ocurridas en las zonas más antiguas del barrio linderas al riachuelo.

La segunda de las razones radica en la robustez de las formas en ensanche. Mientras que la morfología del lado este ha vacilado con dimensiones muy variables y muy grandes, tendiendo a reducirlas y homogeneizarlas con el tiempo, el área de ensanche ha sufrido muy pocas variaciones a este respecto, utilizando un rango dimensional y formal homogéneo y convergente. Las dimensiones estándar de entre 7.000 a 10.000 metros cuadrados, y las formas cuadrangulares de las manzanas, evidencian un adecuado ajuste con las funciones urbanas del barrio, la organización de la parcelación y el cambio tipológico de la edificación. De manera clara, se manifiestan los diferentes grados de plasticidad morfológica de las dos ordenaciones, evidenciando qué formas y en qué situaciones tienden a variar más y cuáles tienden a estabilizarse.

No existe ninguna virtud o defecto en sí mismo en el grado de variación morfológica presentada por los dos ámbitos. Mientras que la ordenación más estable tenderá a resguardar por más tiempo y de forma continua las funciones urbanas que acoge, una ordenación más variable podrá permitir ir acoplando diferentes oportunidades estratégicas o funcionales a su trazado urbano. La ordenación en ensanche ha permitido la consolidación de varias calles con comercio especializado y una zona, en general, preferentemente comercial; mientras que la ordenación sobre las márgenes del río ha posibilitado la proliferación de grandes infraestructuras de movilidad y espacios de alta representatividad simbólica del municipio a partir de sus equipamientos y edificios públicos.

\subsubsection{Variación tipológica}

La variación tipológica del barrio podrá explicarse adecuadamente aludiendo a cuatro fases o ciclos que hemos identificado en nuestra investigación. La datación de los ciclos corresponde a: 1850-1889 (primera construcción masiva de edificaciones en el barrio), 1889-1930 (primer ciclo de reformas), 1930-1975 (primer ciclo de renovación), 1975-2016 (segundo ciclo de reformas). Excluiremos a efectos de explicación morfológica las edificaciones del período colonial anterior a 1850 por no afectar en grado significativo a las variaciones morfológicas posteriores.

Los tipos del primer ciclo entre 1850 y 1889 responden a una arquitectura que busca alejarse de los modos coloniales, según una arquitectura neoclásica primero, y ecléctica después, que sería introducida por la Misão Francesa (Lemos, 1985) en la segunda mitad de siglo. Con lotes estrechos y alargados, las edificaciones, de una o dos plantas, y usos residenciales en su mayoría, configuraron el paisaje edificatorio del barrio. El hinchamiento poblacional derivado de la llegada de inmigrantes europeos introdujo figuras tipológicas precarias como el cortiço, solución que se vincularía a los episodios de fiebre amarilla y cólera morbo en Santa Ifigênia y que motivaron a las autoridades municipales y estatales a inspeccionar el área, promoviendo así los primeros códigos de regulación de la cuestión higiénico-sanitaria en São Paulo.

El segundo ciclo entre 1889 y 1930 nace al amparo de la República y de la cuestión sanitaria, con una nueva burguesía industrial que acumuló el capital suficiente para convertir Santa Ifigênia en un área de excelsas construcciones, hoteles y palacetes, donde el tipo edificatorio crece en altura levemente - los sobrados. Pero en su mayoría, las operaciones tipológicas más significativas serán las de reforma y adecuación de las edificaciones del ciclo anterior que, o bien alteran o bien amplían las construcciones para ir acogiendo progresivamente nuevas funciones comerciales.

El tercer ciclo entre 1930 y 1975 señala el impulso de renovación del barrio bajo los formatos tipológicos permitidos ahora por las nuevas tecnologías, a saber, el hormigón, los elevadores, la nueva ley de 
condominios, y un nuevo lenguaje arquitectónico racional influido por el Movimiento Moderno. Con ello, se verticaliza ${ }^{11}$ el barrio, apoyado en una pujante industria de la construcción. El nuevo formato requerirá realizar alguna operación de amalgamiento de parcelas para poder alcanzar las alturas posibilitadas por unos códigos edificatorios excesivamente conniventes con las interferencias entre edificaciones de distinta clase. Los usos comerciales destinados a los bajos de las nuevas torres complementarían a los usos residenciales en las plantas superiores. Y allí donde se ejecutaron grandes operaciones de expropiación —como en la Avenida Ipiranga-, se incentivó un tipo edificatorio de importantes proporciones que rentabilizase la operación administrativa, y valorizase el nuevo espacio viario.

El último ciclo que hemos datado entre 1975 y 2016 consolida las funciones y tipologías que existen en el barrio para dar servicio, fundamentalmente, a usos comerciales al por menor. Los usos residenciales de las torres introducidas en el anterior ciclo irán saliendo progresivamente y siendo transformados en usos comerciales que atienden a los comercios de las plantas bajas, o prestan servicios técnicos auxiliares. A su vez, comienza a darse una reconversión tipológica de los sobrados eclécticos de principios de siglo hacia galerías comerciales, que cambia profundamente la intensidad comercial de la región, principalmente en la rua Santa Ifigênia. En síntesis, en este último ciclo se produce una parálisis profunda de la renovación predial y se intensifica la reforma, cuya consecuencia más notable es la expulsión casi total de usos residenciales por los comerciales.

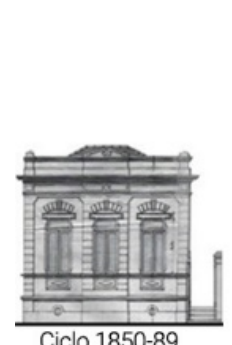

Ciclo 1850-89

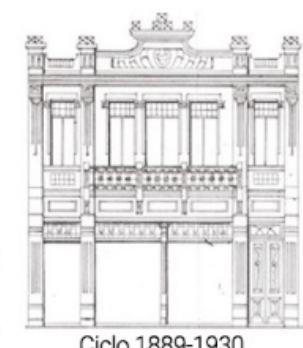

Ciclo $1889-1930$

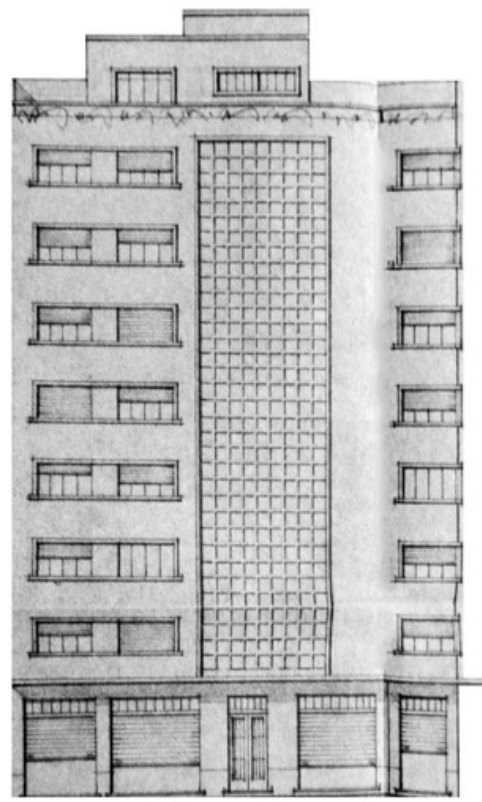

Ciclo 1930-75

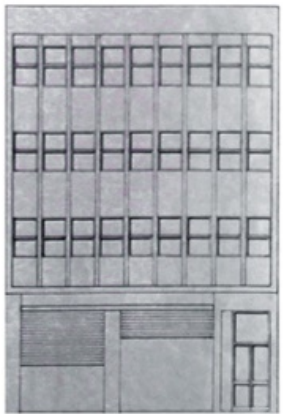

Ciclo 1930-75

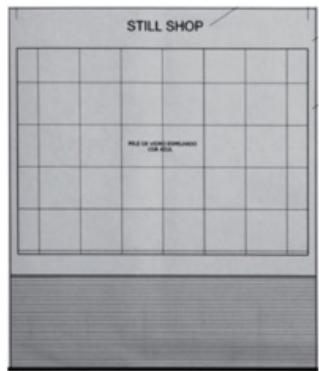

Ciclo 1975-2016

Ilustración 11. Tipos edificatorios según ciclos.

Elaboración el autor, según procesos edificatorios consultados.

\subsubsection{Transición morfológica entre ordenaciones}

Si ahora nos fijamos en las quadras que actúan de charnela entre las dos ordenaciones que componen el barrio observaremos otra característica morfológica significativa - ver ilustración 9 . Para resolver el encuentro entre estas dos ordenaciones surgen quadras análogas a las del ensanche, pero con formatos irregulares en triángulo o trapecio, y de menores dimensiones, que amoldan la ortogonalidad del nuevo tejido a la diagonalidad del antiguo. Su singular localización de mediación entre ambas ordenaciones, sus formas irregulares que dificultan el encaje edificatorio, y sus menores dimensiones relativas, propician su uso como solución a los problemas de articulación y cosido entre las distintas ordenaciones. Y esta articulación ha resultado principalmente de la sustitución edificatoria para albergar espacios libres.

\footnotetext{
${ }^{11}$ Conocido así al proceso de densificación en altura de la edificación.
} 

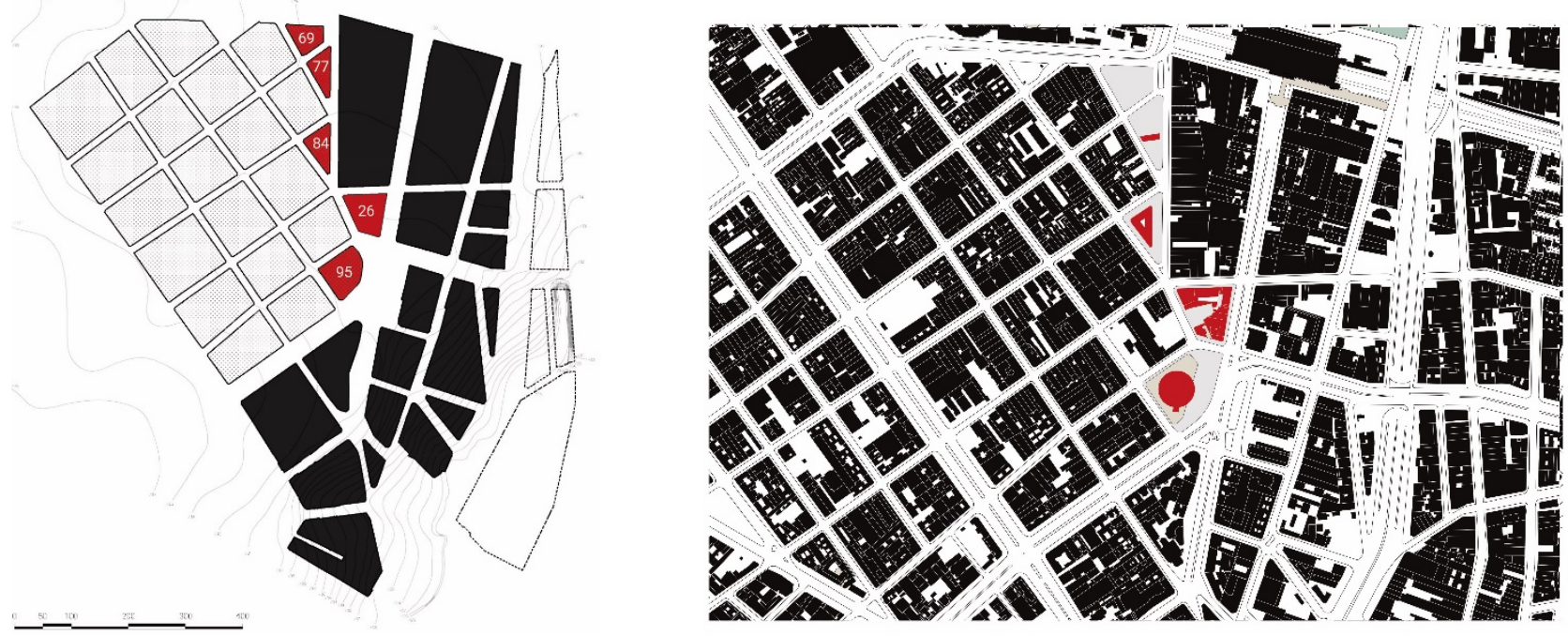

Ilustración 12. Manzanas de transición entre ordenaciones (izquierda) y estado de la edificación actual (derecha). Elaboración el autor, sobre base del MDC de 2004.

Estas piezas de transición morfológica, identificadas por las quadras número 26, 69, 77, 84 y 95, han sido objeto de numerosas intervenciones de transformación. En la actualidad, la quadra 69 ha sido expropiada por la Prefeitura y se encuentra libre de ocupación, siendo usada temporalmente como estacionamiento a cielo abierto, mientras que en la quadra 77 tan solo computa una pequeña construcción; la quadra 84, que albergaba desde la década de 1870 aproximadamente la Igreja Ingleza (protestante), hasta la década de 1950 o 1960, ha sido ocupada desde entonces por dos edificaciones sucesivas, la última de ellas un pequeño shopping de una planta con baja ocupación; en la quadra 26 se han dado varias operaciones de expropiación importantes, acortando el apuntado triángulo original al trapecio actual, siendo ésta la quadra de borde más densificada; finalmente, la quadra 95, donde se emplazaría la residencia de la familia de Marianna Fortes, pasará de plaza pública, tras su expropiación en 1930, a equipamiento del Estado, primero como Garagem Central en los años 1960-70 _ por el que debe su peculiar forma circular-, y después como el actual Poupatempo. Todas estas quadras de borde han variado significativamente en forma o en contenido. Tan solo una de cinco no ha servido histórica o actualmente como dotación pública, confirmando la plasticidad a la que nos referimos para las zonas de transición y su tendencia a una mayor variación hacia fines dotacionales públicos.

De modo que existe una preferencia de transformación de las quadras de 'borde' a favor de la conversión de su régimen privado a dominio público, transformándose parcial o totalmente en largos, vías de paso, plazas, equipamientos $u$ otros objetos urbanos públicos. Estas piezas en charnela muestran un comportamiento evolutivamente más plástico que las ordenaciones a las cuales enlazan y, consecuentemente, una estabilidad menor.

\subsubsection{Irregularidades morfológicas}

Conviene señalar, a su vez, la presencia de irregularidades morfológicas en el barrio de Santa Ifigênia, las hipótesis de su formación y el por qué existen todavía hoy. Entendemos por irregularidades morfológicas aquellas conformaciones singulares de la urbanización que no son características de las ordenaciones que las contienen. La primera irregularidad la constituye el Becco Paysandú, actual rua Abelardo Pinto, localizada en la quadra 58a donde por un tiempo funcionó el Seminário das Educandas —ver ilustración 10. 

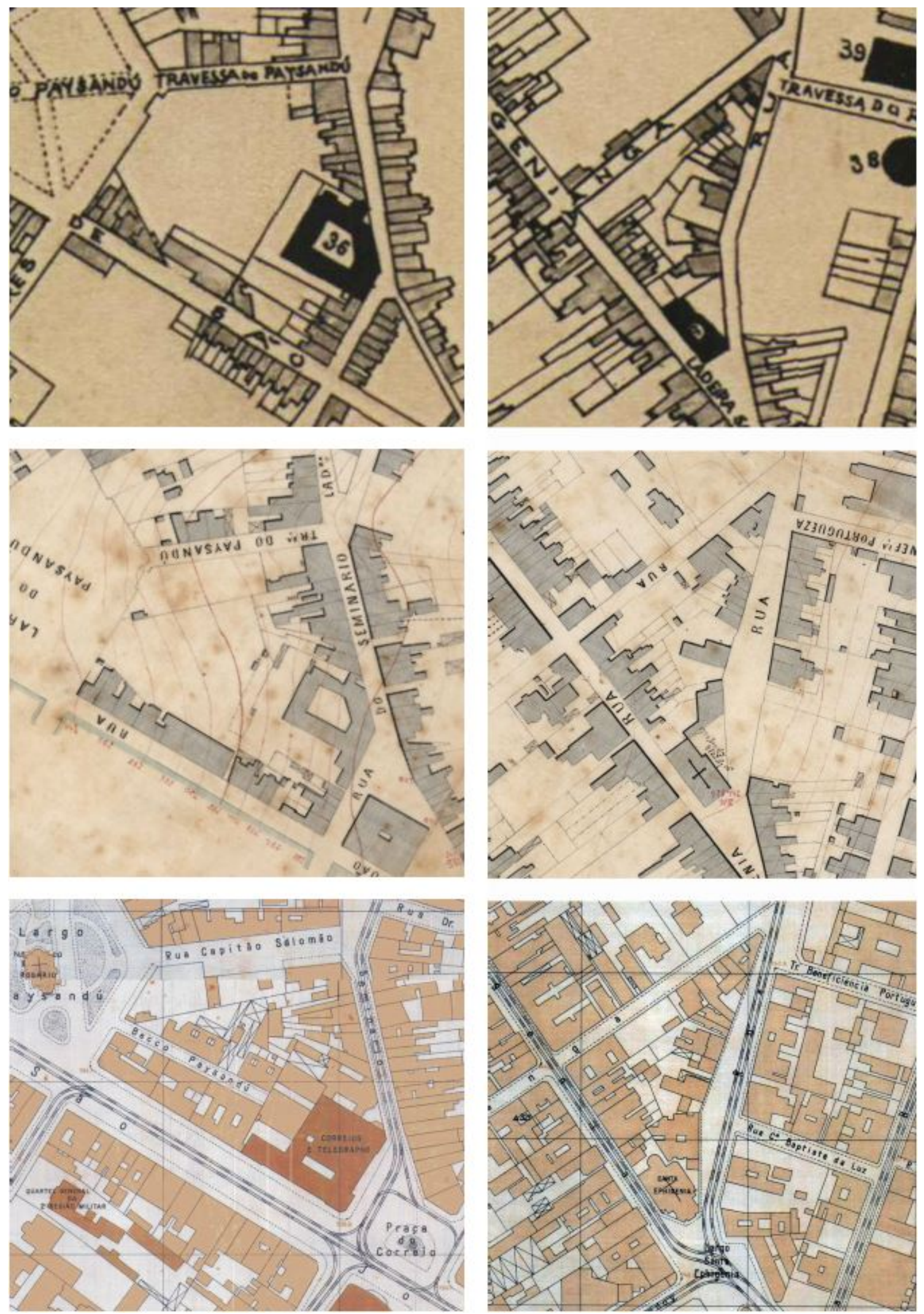

Ilustración 13. Irregularidades morfológicas en el Beco do Payssandú (izquierda) y en la manzana de la Igreja de Santa Ifigênia (derecha).

Plantas de la ciudad de São Paulo para los años 1881, 1892 y 1930. 
Este callejón define el único cul-de-sac de todo el barrio. La manzana responde a un diseño morfológico menos regular que el de ensanche, característico de ordenaciones previas, cogiendo las direcciones principales definidas por la rua Capitão Salomão y la Avda. São João en dos de los laterales, y del Largo de Paiçandú, la Praça Pedro Lessa y la Praça de Correios en los tres restantes. La ilustración 10 muestra la situación de la quadra en los años 1881, 1892 y 1930. En la primera de éstas, el lote de mayores dimensiones ocupa el área central de la quadra, presentando un acceso estrecho desde el Largo. La ocupación de este lote tardó en acontecer más que en el resto del barrio, motivado probablemente por la falta de idoneidad de las características geométricas del mismo, que haría difícil una ocupación con pequeñas edificaciones al uso. El Seminário en primer lugar, y el edificio de Correios e Telégraphos en segundo, actuarían como tapones a la posible abertura de una calle paralela interior con entrada y salida.

A partir de la expropiación de la rua São João, todas las edificaciones de la manzana con frente a ésta fueron retiradas, y el lote anteriormente interior pasaría a mostrar ahora frente para la nueva avenida, pudiendo aprovechar las oportunidades inmobiliarias derivadas. Fruto de esta operación se abrió el callejón interno y se ocupó el espacio sobrante del lote que ahora podía al fin tener un nuevo frente de acceso y aumentar la edificabilidad de la parcela con nuevas construcciones de dimensiones ordinarias.

En la base de la formación del beco ${ }^{12}$ reside, por tanto, la adecuación a las dimensiones usuales de la edificación. Tanto lotes excesivamente pequeños como excesivamente grandes y con geometrías irregulares muestran dificultades de ocupación, al no estar tan adaptados a la oferta inmobiliaria mayoritaria. La falta de oportunidad de venta debió haber dilatado el tiempo en que se dieron las primeras ocupaciones del lote, y fueron precisamente las oportunidades generadas por la transformación viaria las que propiciaron nuevas soluciones para un suelo de gran interés inmobiliario.

En consecuencia, es posible conjeturar que el retardo de la actividad inmobiliaria en zonas que reciben presión de transformación alta es un factor que puede favorecer la emergencia de irregularidades morfológicas. Ello viene justificado por la consolidación progresiva de lotes y edificaciones circundantes a terrenos vagos, cuya estabilidad obliga a la adopción de soluciones singulares para sortear las dificultades de parcelación derivadas de una estructura parcelaria consolidada.

Una segunda irregularidad vendría definida por el ya comentado quiebro en la manzana de la Igreja Santa Ifigênia, mostrada en la ilustración 10. El quiebro es originalmente deudor de la morfología de las primeras manzanas del barrio. La rectificación de la rua Conceição afectó tan sólo al lado par de la misma, y originó el espacio residual en el lado impar. La presencia más o menos consolidada de la edificación, muy similar en los dos primeros períodos, desalentaría la idea de rectificar ambos lados, manteniendo el ensanchamiento resultante.

La importancia de las irregularidades morfológicas radica en que cuentan la historia de la formación de la urbanización, incorporan el tiempo al discurso morfogenético, e informan de situaciones pretéritas que parecerían incongruentes en un análisis que no llevase en cuenta la dimensión temporal, ayudando a comprender las singularidades visibles en el presente.

\section{CONCLUSIONES}

El estudio pormenorizado de la urbanización de Santa Ifigênia nos ha permitido entender los procesos morfológicos generativos que se han sucedido a lo largo del tiempo. La constatación de la tendencia de las quadras a su reducción y fragmentación dimensional no debería hacernos pensar que este proceso haya parado en nuestros días, más bien al contrario; es probable que el proceso continúe ocurriendo en las próximas décadas. De hecho, las propuestas promovidas por la Prefeitura desde 2005 para aumentar el contingente inmobiliario del barrio -conocido como Projeto Nova Luz-, hubiera establecido una nueva fase de reducción y desagregación de manzanas. La extensa quadra 19 aparece en la propuesta subdividida por cuatro nuevas vías de acceso; la manzana 77 habría sido recortada en su vértice más agudo; varias manzanas -la 58b, 65, 67, 68 o la 73, entre otras- incorporarían espacios públicos al interior de las mismas; y otras, como la 93 y 94, sufrirían reducciones en alguno de sus laterales para ampliar el espacio público de estancia. Los $7.500 \mathrm{~m}^{2}$ de manzana representa, a día de hoy, un atractor dimensional medio que, con una horquilla de $\pm 25 \%$, orienta las previsiones de transformación morfológica futuras.

\footnotetext{
12 Literalmente, 'callejón'
} 


\section{BIBLIOGRAFIA}

\section{Obra completa:}

Ab'Saber AN (2004) São Paulo. Ensaios Entreveros. São Paulo: Edusp e Imprensa Oficial do Estado de São Paulo.

Barras R (2009) Building Cycles: Growth and Instability. West Sussex: Wiley-Blackwell.

Gimenez Baldrés E (1996) Parcelaciones Residenciales Suburbanas. La Formación de la Periferia Metropolitana de Valencia. Valencia: Servicio de Publicaciones UPV.

Lemos CAC (1985) Alvenaria Burguesa. São Paulo: Nobel.

Solà-Morales M de (1997) Las Formas del Crecimiento Urbano. Barcelona: Edicions UPC.

\section{Cartografías:}

Planta da Imperial Cidade de São Paulo, con fecha aproximada entre 1765 y 1774.

Planta das Chácaras, sítios e propriedades à volta da Cidade de São Paulo, desde o século XVIII.

Mappa da Imperial Cidade de S. Paulo, 1855.

Mapeamento Digital da Cidade (MDC), 2004 